\title{
As duas faces da vitamina D como terapia adjuvante na COVID-19
}

Erivan de Souza Oliveira'

Marcela Feitosa Matos²

Olga Samara Silva Cavalcante ${ }^{1}$

João Victor Costa Silvestre ${ }^{3}$

Dayane Estephne Matos de Souza ${ }^{4}$

Arlandia Cristina Lima Nobre de Morais ${ }^{1}$
No final do ano de 2019 em Wuhan, província de Hubei, China, surgiu o primeiro caso de covid-19, causada pelo agente etiológico denominado de síndrome respiratória aguda grave coronavírus 2 (SARS-CoV-2), que rapidamente se espalhou por diversos países do mundo [13].

Atualmente, na literatura existem vários estudos que informam que a vitamina $D$ pode reduzir as taxas de replicação viral e a concentração de citocinas próinflamatórias, através mecanismos relacionados a estimulação de defensivas e catelicidinas [4-6].

Ressalta-se que a vitamina $D$ é uma vitamina lipossolúvel encontrada em alimentos, como por exemplo, salmão, cogumelos, sardinhas, ovos, iogurte, fígado de boi e ostras. Também é produzida pelo sistema endógeno, quando os raios ultravioletas da luz solar atingem a pele e desencadeiam a síntese da vitamina $\mathrm{D}$. Existem também, diversos alimentos que possuem a adição de vitamina $D$, além da suplementação dietética [7]. Essa vitamina está envolvida na regulação do crescimento e diferenciação celular, e pode prevenir a proliferação e as metástases de células cancerígenas [8].

Vale salientar que em alimentos enriquecidos e suplementos dietéticos, a vitamina $D$ é disponível em duas formas, a forma de vitamina D2, denominada ergocalcidiol, fabricada pela radicação ultravioleta do ergosterol em fungos e a vitamina D3, denominada colecalciferol, fabricada pela irradiação do 7-desidrocolesterol da lanolina e a conversão química do colesterol, ambas as formas são equivalentes, porém em altas doses a vitamina D2 é menos potente que a D3 $[9,10]$.

Diversas pesquisas mostram que a hipovitaminose de vitamina $\mathrm{D}$ pode comprometer o metabolismo ósseo, causar o desenvolvimento de doenças metabólicas como diabetes mellitus, obesidade e hipertensão, além de complicações gestacionais [11-14]. Podendo também está associada ao aumento do risco de infecção respiratória viral aguda e pneumonia adquirida na comunidade [15]. Alguns estudos destacam resultados positivos na utilização dessa vitamina para o tratamento da covid-19 [14].

McCartney et al. [15] reporta que a utilização da vitamina $D$ reduziu in vivo a expressão do receptor dipeptidil peptidase-4 (DPP-4/CD26) que possivelmente interage com o domínio S1 da glicoproteína espiga da covid-19. Eles ainda ressaltam que o uso da vitamina $D$ pode diminuir as sequelas imunológicas causadas por interferon-gama 4 e a

\footnotetext{
${ }^{1}$ Universidade de Fortaleza, Curso de Farmácia. Avenida Washington Soares, 1321, Edson Queiroz, CEP.: 60811-905, Fortaleza, Ceará, Brasil. Correspondência: erivan@edu.unifor.br.

${ }^{2}$ Universidade Estadual do Ceará, Nutricionista

${ }^{3}$ Graduado em Farmácia

${ }^{4}$ Graduanda em Enfermagem
}

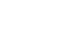

Como citar este artigo / How to cite this article

Oliveira ES et al. As duas faces da vitamina D como terapia adjuvante na COVID-19. InterAm J Med Health 2020;3:e202003023. 
a elevação persistente da interleucina 6. Os mesmos informam que não foi encontrado na literatura evidências que demonstrem que a suplementação de vitamina D doses de 20 a 50 microgramas por dia apresentem efeitos adversos.

Grant et al. [14] destaca que através de diversos mecanismos, a vitamina $D$ pode reduzir o risco de infecções virais e a deficiência dessa vitamina pode contribuir para a síndrome do desconforto respiratório agudo. Os mesmos sugerem que para a prevenção de infecção disseminação principalmente da covid-19 devem fazer - uso de 10.000 Unidades o uso de 10.000 Unidades internacionals (UI) por dia de vitamina D3 por algumas semanas para aumentar rapidamente as concentraçoes de 25-hidroxi-vitamina D, seguidas por $5000 \mathrm{UI} / d i a$. Os mesmos indicam que para o tratamento da covid-19, deve-se utilizar doses mais altas de vitamina D3. Entretanto, através desta observação, vale mencionar que a maioria dos ensaios clínicos não relataram a redução significativa da proliferação do SARSCoV-2 com a suplementação de vitamina D.

Greiller et al. [16] ressalta que na cultura de células epiteliais respiratórias humanas in vitro a vitamina $\mathrm{D}$ modulou a expressão e secreção do interferon tipo 1 , quimiocinas incluindo CXCL8 e CXCL10 e citocinas próinflamatórias, como TNF e IL-6. No entanto, eles sugerem a realização de mais estudos que possam esclarecer os efeitos dos metabólitos da vitamina D contra a replicação viral.

Segundo Wimalawansa [17] os pacientes que possuem deficiência de micronutrientes, principalmente aqueles com hipovitaminose D (visto a redução da produção de citocinas anti-inflamatórias), apresentam os maiores riscos de desenvolver doenças virais. Recomendando, desta forma, o uso de suplementos de vitamina D e/ou exposição ao sol do verão para aumentar as concentrações séricas de 25 -hidróxi-vitamina $\mathrm{D}$ acima de $30 \mathrm{ng} / \mathrm{mL}$ para fortalecer o sistema imunológico. Ele ressalta ainda que para ocorrer efeitos Dar ocorrer efeitos adversos com 25.000 UI durante muitos meses ou tomar 1 milhão de U diariamente por alguns dias.

Gasmi et al. [18] reporta que a suplementação com vitamina $D$ é eficaz quando é utilizada antes do início da infecção do trato respiratório. No entanto, para o tratamento dos pacientes em risco de covid-19, recomendado aumentar as concentrações de 25-hidróxivitamina D ente 40-60 ng/mt (100-150 - hmo/h), considerando a utilização de 10.000 UI por dia de vitamina D3 por durante algumas semanas com o objetivo aumentar rapidamente as concentrações, seguidas de

Neste contexto, cabe mencionar que a Sociedade Brasileira de Endocrinologia e Metabologia (SBEM) informou que até o momento não existe, recomendação aprovada para a prescrição de suplementação de vitamina D visando efeitos além da saúde óssea. Ressalta ainda que a utilização de altas doses de colecalciferol, pode ser deletéria ao esqueleto, promover o aumento da reabsorcão óssea e do risco de quedas e fraturas. Podendo também desencadear hipercalcemia (causar danos renais) hipercalciúria [19].

Destaca-se que a grande parte da população se automedica com vitaminas e polivitamínicos, e o consumo desorientado vem crescendo rapidamente devido a facilidade de aquisição e principalmente por carência de informações. Entretanto, o uso excessivo desses medicamentos pode causar grandes agravos pode se acumular no tecido adiposo e provocar efeitos tóxicos no organismo humano [21], tendo como manifestação mais frequente a calcinose, que consiste na extensa mineralização dos tecidos moles e artérias, podendo causar um comprometimento do sistema cardiovascular [22]. Já a hipovitaminose pode desencadear diversas patologias que podem ocasionar dores nos ossos e fraqueza muscular, por isso, deve ser levada em consideração no diagnóstico principalmente dos pacientes com covid-19, pois o diagnóstico diferencial pode melhorar o prognóstico dos pacientes [23].

A produção endógena e a síntese de vitamina $D$ vai depender de diversos fatores, como estação do ano, hora do dia, cobertura das nuvens, poluição da atmosfera, quantidade de melanina da pele e a utilização de protetor solar [6,7,24]. Alguns estudos sugerem, que a exposiça solar deve ocorrer de 5 a 30 minutos e por volta de 10 15 horas, no mínimo duas vezes por semana, sem o uso de protetor solar, pessoas que não realizam exposição devem incluir na sua alimentação boas fontes de vitamina D ou utilizar suplementação dietética para atingir os níveis recomendados de ingestão $[25,26]$.

A recomendação da vitamina $D$ para pessoas saudáveis vária de acordo com a faixa etária, crianças de 0 a 12 meses devem ingerir $10 \mathrm{mcg}$ o que equivale 400 $\mathrm{Ul}$, pessoas de 1 a 70 anos o recomendado é $15 \mathrm{mcg}$ ou $600 \mathrm{UL}$ maiores de 70 anos devem consumir $20 \mathrm{mcg}$ ou 800 UI7. Existem grupos mais susceptíveis à deficiência vitaminada $\mathrm{D}$ que merecem atenção redobrada, como por exemplo, pessoas que fazem o uso de anticonvulsivante diuréticos, múltiplas medicações, hemodiálise e possui doenças crônicas não transmissíveis [27,30]. Ressaltase que indivíduos que possuem doenças crônicas não transmissíveis e processos inflamatórios aumentados apresentam níveis séricos baixos de vitamina $D$ e a suplementação dessa vitamina tem como objetivo aumentar a resposta celular imune e a expressão de genes referentes a moléculas antioxidantes, melhorando desta forma, a resposta imunológica. Ademais, tem patologias que comprometem a função hepática e renal que podem agravar ainda mais a deficiência de vitamina $D$.

Atualmente, só se tem falado mais sobre a hipovitaminose da vitamina $D$ e sua suplementação, visto que estudos estão relatando benefícios da suplementação desta vitamina em relação a covid-19, mas não é disseminado o possível risco de uma hipervitaminose, esta falta de informação é considerada um risco para a saúde da população, pois grande parte das pessoas realizam a compra sem a prescrição de um profissional.

É de suma importância discutir o uso de medicamentos vitamínicos e polivitamínicos e sua possível toxicidade, pois atualmente o mundo vem enfrentando uma pandemia causada pelo SARS-CoV-2 e a procura por fármacos que melhorem a imunidade tem aumentado cada vez, surgindo, desta forma, a disseminação de informações equivocadas.

A exposição solar de acordo com as recomendações já citadas, mais uma dieta equilibrada e individualizada consegue fornecer todas as vitaminas, minerais em quantidade suficiente para a manutenção das diversas funções metabólicas do nosso organismo, a suplementação é indicada somente em casos específicos e deve ser analisada por profissionais habilitados. Quantidades insuficientes ou em excesso desses micronutrientes podem ocasionar manifestações patológicas relacionadas respectivamente hipovitaminose ou hipevitaminose. Vale ressata existem medicamentos que aumentam o catabolismo da vitamina D (por exemplo, anticonvulsivantes, izoniazida, rifampicina e teofilina) por serem indutores enzimáticos. Oliveira e Morais1 destacam que os profissionais de saúde precisam avaliar cada paciente tendo em vista a fisiopatologia da doença e os fatores que podem prejudicar o tratamento dos pacientes.

É possível observar que os resultados obtidos não são unânimes ao definir a dose ideal de vitamina $D$ para suplementação dos pacientes com covid-19. Sugere-se a realização de estudos clínicos adicionais que possam avaliar a eficácia e as concentrações ideais dessa vitamina para o tratamento (se possivel) dos pacientes com SARS-CoV-2, pois a vitamina $D$ não é isenta de efeitos adversos e uso inadequado pode ocasionar problemas gastrintestinais e metabólicos que podem agravar os sintomas da covid-19.

\section{REFERÊNCIAS}

1. Oliveira ES, Morais ACLN. COVID-19: uma pandemia que alerta à população. InterAmerican Journal of Medicine and Health. 2020;3:e202003008. doi: 10.31005/iajmh.v3i0.80

2. Zou L, Ruan F, Huang $M$, Liang L, Huang $H$, Hong $Z$, et al. Positive RT-PCR Test Results in Patients Recovered From COVID-19. SARS-CoV-2 Viral Load in Upper Respiratory Specimens of Infected Patients. The New England Specimens of Infected Patients. The New England

3. Araújo-Filho JAB, Sawamura MVY, Costa AN, Cerri GG, Nomura CH. Pneumonia por COVID-19: qual o papel da imagem no diagnóstico? doi: Bras $\quad \begin{array}{ll}\text { Pneumol. 2020;46(2):e20200114. } \\ 10.36416 / 1806-3756 / \mathrm{e} 20200114\end{array}$ 4. Gasmi A, Noor S, Tippairote T, Dadar M, Menzel A, Bjørklund G. Individual risk management strategy and potential therapeutic options for the COVID-19 pandemic. Journal Pre-proof. 2020. Doi: $\quad$ https://doi.org/10.1016/j.clim.2020.108409 5. Herr C, Shaykhiev R, Bals R. The role of cathelicidin and defensins in pulmonary inflammatory diseases. Expert Opin Biol Ther. 2007: 7(9):1449-61. doi: $10.1517 / 14712598.79 .1449$ 6. Huang C, Wang Y, Li X, Ren L, Zhao J, Hu Y, et al. Clinical features of patients infected with 2019 novel coronavirus in Wuhan, China. The Lancet. 2020; 395(10223): 497-506. doi: 10.1016/50140-6736(20)30183-5. 7. Institute of Medicine, Food and Nutrition Board. Dietary Reference Intakes for Calcium and Vitamin D. Washington, DC: National Academy Press, 2010. 
8. Andrade PCO, Castro LS, Lambertucci MS, Lacerda MIPB, Araújo VPRJ, Bremm TAL, et al. Alimentação, fotoexposição e suplementação: influência nos níveis séricos de vitamina D. Rev Med Minas Gerais. 2015; 25(3): 432-437.

9. Zhang $H$, Penninger JM, Li $Y$, Zhong $N$, Slutsky AS. Angiotensin-converting enzyme 2 (ACE2) as SARS-CoV-2 receptor: molecular mechanisms and potential therapeutic target. Intensive Care Med. 2020;
$46.586-590$ doi: $10.1007 / 500134-020-05985-9$.

10. Centers for Disease Control and Prevention. Coronavirus Disease 2019 (COVID-19) [homepage Coronariss Disease 2019 (COVD-19) na internet]. People who are at higher risk for severe illness. [acesso em 07 de abril de 2020]. Disponivel em from:https://www.cdc.gov/coronavirus/2019-ncov/ need-extra-precautions/people-at-higher-risk.htm

11.BouillonR, OkamuraWH, NormanAW. Structure-function relationships in the vitamin $D$ endocrine system. Endocr Rev. 1995; 16(2):200-57. doi: 10.1210/edrv-16-2-200

12. Cantorna MT, Mahon BD. D-hormone and the immune system. J Rheumatol Suppl. 2005; 76:11-20.

13. Li YC, Qiao G, Uskokovic M, Xiang W, Zheng W, Kong J. Vitamin D: a negative endocrine regulator of the renin-angiotensin system and blood pressure. I Steroid Biochem Mol Biol. 2004;8990(1-5):387-92. doi: $10.1016 / \mathrm{j} . \mathrm{jsbmb} .2004 .03 .004$

14. Grant BM, Lahore $H$, McDonnell SL, Baggerly CA, Francês $C B$, Aliano JL, Bhattoa HP. Why vitamin D clinical trials should be based on 25-hydroxyvitamin D concentrations. J Steroid Biochem Mol Biol. 2018;

15. McCartney DM, Byrne DG. Optimisation of Vitamin D Status for Enhanced Immuno-protection Against Covid-19. Ir Med J. 2020:113(4):58-61.

16. Greiller $\mathrm{CL}$, Martineau AR. Modulation of the Immune Response to Respiratory Viruses by Vitamin $D$. Nutrients. 2015;7(6):4240-70. doi: 10.3390/nu7064240.

17. Wimalawansa SJ. Global epidemic of coronavirus-covid-19: what can we do to minimize risks. EJBPS, 2020; 7(3): 432-438.
18. Gasmi A, Noor S, Tippairote T, Dadar M, Menzel A, Bjørklund G. Individual risk management strategy and potential therapeutic options for the COVID-19 pandemic Journal Preproof. 2020. doi: $\quad$ https://doi.org/10.1016/j clim.2020.108409 19. Sociedade Brasileira de Endocrinologia e Metabologia (SBEM) e da Associação Brasileira de Avaliação Óssea e Osteometabolismo (ABRASSO) [homepage na internet]. Vitamina D e Covid-19 [acesso em 16 de abril 2020]. Disponível em: https://www endocrino. org 2020). Disponivel em: hips/Muw.endocino.

20. Premaor MO, Furlanetto TW. Hipovitaminose D em adultos: en-tendendo melhor a apresentação de uma velha doença. Arq Bras Endocrinol Metab. 2006; 50(1):25-37. doi: 10.1590/\$0004-27302006000100005.

21. Velásquez-Meléndez G., Martins IS, Cervato AM, Fornés NS, Marucci MFN. Consumo alimentar de vitaminas e minerais em adultos residentes em área metropolitana de São Paulo, Brasil. Rev. Saúde Pública. 1997; 31(2): 57-62. doi: 10.1590/50034-89101997000200009. 22. Schuchd NJ, GarciaVC, Martini LA. Vitamina De doenças endocrinometabólicas. Arq Bras Endocrinol Metab. 2009; 53(5):625-33. doi: 10.1590/50004-27302009000500015.

23. Premaor MO, Furlanetto TW. Hipovitaminose $D$ em adultos: Entendendo melhor a apresentação de uma velha doença. Arquivos Brasileiros de Endocrinologia \& Metabologia. 2006; 50(1):25-37. 24. Wharton B, Bispo N. Rickets. The Lancet. 2003. 362:1389-400. doi: 10.1016/\$0140-6736(03)14636-3 25. Centers for Disease Control and Prevention. Coronavirus Disease 2019 (COVID-19) [homepage na internet]. People who are at higher risk for severe illness. [acesso em 07 de abril de 2020]. Disponível em: from:https://www.cdc.gov/coronavirus/2019-ncov/ extra-precautions/people-at-higher-risk.htm 26. Lang PO, Aspinall R. Vitamin D Status and the Host Resistance to Infections: What It is Currently (Not) Understood Clin Ther 2017 39.930-945 doi:10.1016/j.clinthera.2017.04.004
27. Holick MF. Vitamin D: extraskeletal health Rheum Dis Clin North Am. 2012:38(1):141 60. doi: doi.org/10.1016/j.rdc.2012.03.013.

28. Mitri J, Muraru MD, Pittas AG. Vitamin D and type 2 diabetes: a systematic review. Eur J Clin Nutr. 2011;65(9):1005-15. doi: 10.1038/ejcn.2011.118

29. Marques CDLM, Dantas AT, Fragoso TS, Duarte ALBP. A importância dos níveis de vitamina $D$ nas doenças autoimunes. Rev Bras Reumatol. 2010;50(1):6780. doi: 10.1590/50482-50042010000100007.

30. Ginter JK, Krithika S, Gozdzik A, Hanwell H, Whiting $S$, Parra EJ. Vitamin D status of older adults of diverse ancestry living in the greater Toronto area. BMC Geriatrics. 2013;13(1):66. doi: 10.1186/1471-2318-13-66 